\title{
Rapid Monitoring of Listeria monocytogenes in Raw Minced Meat Using Real-Time Polymerase Chain Reaction
}

\author{
Fatima El Habib ${ }^{1}$, Samira Senouci ${ }^{2}$, Abdelmoula El Ouardi ${ }^{3}$, Lahcen Ouchari ${ }^{4}$, \\ My Mustapha Ennaji ${ }^{5}$ \\ 1, 2,3 (Department of Microbiology and Food Hygiene/National Institute of Hygiene, Rabat, Morocco) \\ ${ }_{1,3,5}$ (Laboratory Virology, Hygiene and Microbiology/Faculty of Sciences and Techniques \\ Mohammedia/University Hassan II Mohammedia-Casablanca, Morocco) \\ ${ }^{4}$ (National Center for Scientific Research, Rabat, Morocco)
}

\begin{abstract}
Listeria monocytogenes is a pathogenic bacteria of great concern in the food industry due to its wide distribution in the environment, its ability to grow at low temperatures and relatively high salt levels, and the potential severity of the infection with high mortality, mainly in pregnant women, the elderly and immunocompromised patients. Food-borne listeriosis remains a public health threat.

One hundred forty two minced raw meat samples were collected from various points (processing plants, hotels, restaurants, retail outlets, caterers and wholesalers) and were analyzed for the detection of $L$. monocytogenes by conventional culture and Real-time polymerase chain reaction (Real-time PCR).

Our results showed frequent contamination of raw minced meats (21\%). Our statistical analysis showed a relatively correlation $\left(R^{2}=0.637, p<0.01\right)$ between the two methods, while the sensitivity, specificity, and positive and negative PCR method predictive values were respectively 30, 92, 37 and 97\%. Continuous environmental monitoring schemes for L. monocytogenes are of major importance to identify potential contamination sources and as an early warning system for meat business operators. Hence, the detection of $L$. monocytogenes by Real-time PCR method allows good control of the health risk.
\end{abstract}

Keywords: Control, Health risk, Listeria monocytogenes, Minced raw meat, Real-time PCR

\section{INTRODUCTION}

The quality and safety of foods, both of animal and plant origin, is of outmost importance for governments, industries and consumers. It is well recognized that pathogens, such as Listeria spp. particularly Listeria monocytogenes, can be transmitted along the food chain and be a source of human illness; they can contaminate foods and multiply under suitable conditions [1]. L. monocytogenes is frequently associated with foodborne disease outbreaks that are characterized by widespread distribution and relatively high mortality rates [2]. Furthermore, not all L. monocytogenes strains are equally capable of causing disease in humans. Of the 13 serovars of $L$. monocytogenes, only three i.e., $1 / 2 \mathrm{a}, 1 / 2 \mathrm{~b}$ and $4 \mathrm{~b}$, cause more than $90 \%$ of the human cases [3].

In recent years there has been a large increase in the production and consumption of meat and meat products, at the same time there is an increasing consumer demand for a health, safe and balance diet [4]. Meat and meat products are excellent substrates for microorganisms growth [5]. In fact, L. monocytogenes may also survive for a long time in meat processing facilities [6], which is particularly related to its psychrotrophic nature [7], its ability to attach and form resistant biofilms $[8,9]$ and its potential for contamination of raw and uncooked meats such as raw minced meat (beef or poultry meat) [10].

The microbiological analysis of meat remains a challenging task for virtually all assays and technologies, especially for particular pathogenic Listeria species [11]. The problems may be due to: (i) the complexity of meat and composition, (ii) the heterogeneous distribution of low levels of pathogens, (iii) the stress suffered by the microorganisms during the processing of foods and (iiii) the presence of bacteria from the normal microbiota, especially in raw meats. Thereby, classical microbiological methods for detection of Listeria spp. involve the use of pre-enrichment and/or specific enrichment, followed by the isolation of the bacteria in solid media and a final confirmation by biochemical and/or serological tests [12, 13]. However, these procedures are not always effective (e.g. viable but not culturable -VBNC-forms) [12, 13], and are extremely labour intensive, requiring a long time (form days to weeks) to yield a conclusive result. During the past decades, different alternative have been developed to overcome these disadvantages, and a number of molecular methods have been devised to reveal the presence of undesirable microorganisms in different food matrices such as those based on the Polymerase Chain Reaction (PCR) or Real-time PCR [14].

PCR can be superior to culture for detecting the main pathogens in meat samples. The aim to rapidly detect multiple microorganisms in one run is difficult but needed by the food industry and food safety $[15,16]$. Real-time PCR has greatly increased the speed and sensitivity of PCR-based detection methods, but the terms "rapid" and "sensitive," when applied to PCR as a detection method for foodborne pathogens, must be used with 
caution [13]. However, Real-time PCR detection of the bacteria in food samples is currently done following the pre-enrichment culture because of the inhibitors in food samples [17, 18].

Additionally other rapid methods using Chromogenic agars, the presumptive identification of $L$. monocytogenes is possible after $24 \mathrm{~h}$, compared with 3-4 days using Oxford and other conventional agars [19]. Chromogenic media is done according to enzymes expressed by the pathogen and production of acids by the fermentation of sugars. Different antimicrobials are added to the media to obtain sufficient selectivity. Chromogenic media is the most used culture confirmation method because of its easy preparation and interpretation [20].

In the present work our aim was to evaluate the basic situation and the potential persistence of $L$. monocytogenes strains in minced raw meat using qualitative methods: ISO 11290-1 standard method, chromogenic and molecular diagnostics (Real-time PCR) and to determine correlation between methods.

\section{Food samples and bacterial isolation}

\section{MATERIALS AND METHODS}

In total, 142 minced raw meats samples (Beef or chicken origin) were collected from various local points (processing plants, hotels, restaurants, retail outlets, caterers and wholesalers) in Rabat, Morocco. Samples were transported in clean plastic bags chilled on ice to the laboratory within one hour after sampling. Isolates were recovered using standard laboratory methods for the isolation of $L$. monocytogenes from food (ISO 11290-1:1996) [21]: Examinations for Listeria were performed using a two-step enrichment procedure. $25 \mathrm{~g}$ of raw minced meat was placed into a bag containing $225 \mathrm{~mL}$ of Half Fraser's broth (Oxoid, CM0895) then meat homogenization was incubated for $24 \mathrm{~h}$ at $30^{\circ} \mathrm{C}$. A subset of $0.1 \mathrm{ml}$ was then incubated in $10 \mathrm{ml}$ of Fraser broth (Oxoid, CM0895) for $24 \mathrm{~h}$ at $37^{\circ} \mathrm{C}$. Subsequently, subsets were plated onto Palcam agar (Oxoid, CM0877), Oxford agar (Oxoid, CM0856), Oxoid Chromogenic Isolation Listeria Agar (Oxoid, CM1080) and Brillance Listeria Agar (Oxoid, CM1084) which were then incubated for $48 \mathrm{~h}$ at $37^{\circ} \mathrm{C}$. Listeria-like colonies were streaked onto Oxoid Chromogenic Identification Listeria Agar (Oxoid Ltd.) supplemented with Listeria Selective Supplement and Listeria Differential Supplement (Oxoid Ltd.) and incubated for $48 \mathrm{~h}$ at $37{ }^{\circ} \mathrm{C}$. Presumptive L. monocytogenes colonies on the Chromogen agar were streaked onto sheep blood agar (Oxoid Ltd.) for appraisal of hemolysis (CAMP test). To identify other Listeria species, the API Listeria Identification Kit was used (Api 18R Biomérieux) in accordance with the manufacturer's instructions. The sensitivity of qualitative detection (presence/absence) tests is then defined by the quantity of meats examined. In many cases, the requirement of detection is less than one cell per $25 \mathrm{~g}$ of food, as small numbers of some pathogens may be sufficient to cause disease.

\section{Detection of $L$. monocytogenes by Real-time PCR}

The Real-time PCR approach relies on the optical detection of amplification products by measuring the fluorescent signal generated by either intercalating dyes or specific dual-labeled probes. Further, most of Realtime PCR methods use DNA extraction, followed by Real-time PCR for rapid and sensitive detection, as well as for enumeration of L. monocytogenes in meat. Following the TaqMan ${ }^{\circledR}$ L. monocytogenes Detection Kit protocol (Applied Biosystems PN 4366102): Perform pre-enrichment consists of growing the specific pathogen from a selected sample, Preparing Samples, DNA extraction and Real-time PCR: Reactions were run on a 7500 Real-Time PCR System (Applied Biosystems, Foster City, USA). The amplification curves of Real-Time PCR were processed and the concentrations determined using the StepOne software version 2.0 software (Applied Biosystems, Foster City, USA). Specificity and sensitivity of Real-time PCR assays were determined by using cultures of L. monocytogenes strain ATCC 19111. Methods were controlled according to the instructions of the following ISO standards: 22119, 20836, 20837 and 20838 [22, 23, 24, 25].

We examined the correlation between the two methods by calculating a Pearson correlation coefficient using the MedCalc software, version 12.6.1.0 (MedCalc Software bvba, Belgium, 2012). As a result we calculated the sensitivity, specificity and predictive values of Real-time PCR method considering the culture method as the reference method for the detection of L. monocytogenes.

\section{RESULTS}

L. monocytogenes was detected in $21 \%$ (30/142) samples: Respectively, $14 \%(20 / 142)$ by the classically method and $11 \%(16 / 142)$ by Real-time PCR (Table 1$)$.

Even though it was statistically significant, the correlation between the results by culture and by Real-time PCR was relatively significant, as shown in Figure $1\left(\mathrm{R}^{2}=0.6374, \mathrm{p}<0.01\right)$, (Fig. 1$)$.

Considering the culture method as the reference method for the detection of L. monocytogenes, the sensitivity, specificity, and positive and negative Real-time PCR method predictive values were respectively 30 , 92, 37 and $97 \%$ (Table 1). 


\section{DISCUSSION}

In recent years there has been an increase in the number of Real-time PCR assays which are widely used for the detection of L. monocytogenes in meat [26, 27, 28].

However, the PCR does not distinguish among viable and dead bacterial cells. DNA from bacterial dead cells can serve as a template for the PCR many days after cell viability has been lost [12]. This inability has impaired the implantation of the PCR for routine monitoring in food microbiology laboratories, where metabolically injured or non-viable cells are generally present after the stress that bacteria suffer during food processing and conservation.

In this study, L. monocytogenes was detected in $21 \%(30 / 142)$ samples, likewise, it was detected in 23 of $211(10.9 \%)$ minced beef samples in a retail study in Switzerland in the first half of the year 2000 [29]. A high prevalence of L. monocytogenes $(52 \%)$ was observed in a survey of 100 retail samples of minced beef in Alberta, Canada, in late spring and summer 2001 [30].

Even though, the presence of $L$. monocytogenes can be masked in applied cultural assays by, e.g., $L$. innocua or by the autochthonous microflora of the food matrix and specific antimicrobial components in foods $[31,32]$. In fact, of the 10 samples positive by Real-time PCR and negative by culture, four samples $40 \%(4 / 10)$ are positives for $L$. innocua. The detection of L. monocytogenes in foods is also hampered by the high population of competitive microflora, the low levels of the pathogen, and the interference of inhibitory food components.

The positive predictive value (PPV) of the Real-time PCR compared to culture is low ( $\mathrm{PPV}=37 \%$ ) (Table1). This means that for the same sample, a concentration of L. monocytogenes determined by Real-time PCR will not necessarily be confirmed by culture. In contrast, the negative predictive value (NPV) is excellent and is $97 \%$. Therefore, it is very likely that nondetectable result by Real-time PCR will be accompanied a nondetectable result in culture. In the current study, 126 samples were negative by Real-time PCR. Of these, only 14 were culture positive, indeed various studies have reported the presence of Real-time PCR inhibitors in meat samples $[17,18]$. The Real-time PCR method could, thanks to its high VPN in the raw minced meat, be used in an optical screening for ensure rapidly of the absence of L. monocytogenes without having to resort to culture. In contrast, the low PPV of the Real-time PCR method involves, in the case of a positive result, the need for culture that is currently the reference method. In our study, this occurs for $63 \%$ of the samples, which limits the usefulness of the Real-time PCR method for the microbiological monitoring of raw minced meat [33, 34].

Table 1: Comparison of the detection of L. monocytogenes by Real-time PCR and Culture (Standard method) in raw minced meat $(n=142)$

\begin{tabular}{|c|c|c|c|c|}
\hline \multirow{3}{*}{ Detection by Real-time PCI } & \multicolumn{2}{|c|}{ Detection by Culture } & \multirow{3}{*}{ Total } & \multirow{3}{*}{ predictive Value } \\
\hline & Positive & Negative & & \\
\hline & & & & \\
\hline Positive & 6 & 10 & 16 & $\mathrm{PPV}^{\mathbf{c}}=0,37$ \\
\hline Negative & 14 & 112 & 126 & $\mathrm{NPV}^{\mathrm{d}}=0,97$ \\
\hline Total & 20 & 122 & 142 & \\
\hline Sensitivity and Specificity & Sensitivity $^{\mathrm{a}}=0.30$ & Specificity $^{\mathbf{b}}=0.92$ & & \\
\hline
\end{tabular}

a Sensibility $=$ true positive/ (true positive + false negative)

b Specificity $=$ true negative/ (true negative + false positive)

c PPV (Positive Predictive Value) $=$ true positive/ (true positive + false positive)

d NPV $($ Negative Predictive Value $)=$ true negative/ (true negative + false negative $)$

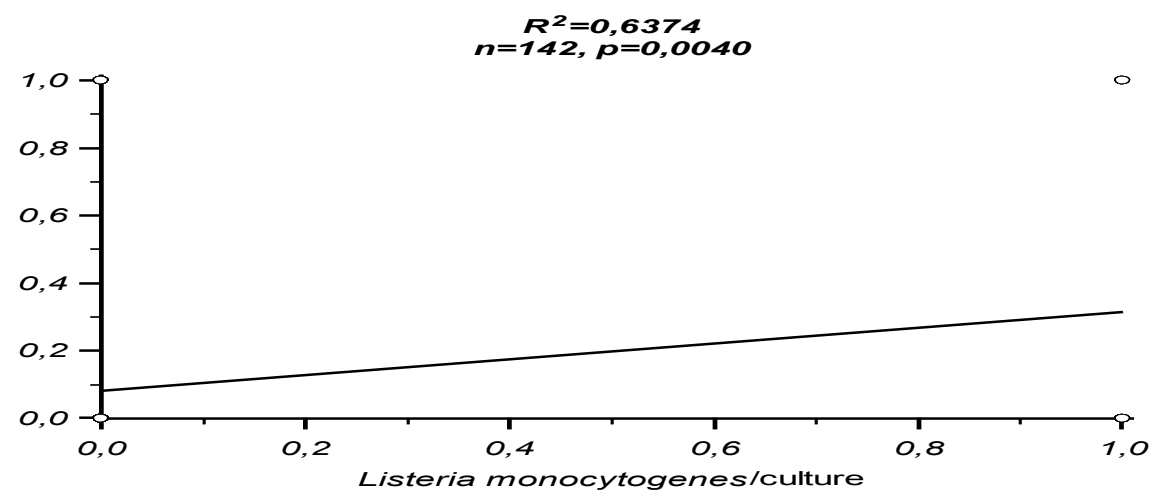

Figure 1: Correlation between L. monocytogenes obtained by Real-time PCR with those obtained by culture in raw minced meat 


\section{CONCLUSION}

The specificity and sensitivity of Taq Man real-time PCR technology for detecting L. monocytogenes in raw minced meat were high, and the assay could be completed within $2 \mathrm{~h}$. This method could be used to detect other food samples contaminated by L. monocytogenes and identify the cause of food-borne Listeriosis outbreaks.

Production of meats free from $L$. monocytogenes contamination remains a challenge for the meat industry. Proactive approaches beyond "plant floor inspection" and "test and hold" protocols are needed in order to effectively protect consumers. Furthermore, continuous environmental monitoring schemes for $L$. monocytogenes are of major importance to identify potential contamination sources and as an early warning system for meat business operators.

\section{ACKNOWLEDGEMENTS}

We thank the staff of the Department Microbiology Food and Hygiene in National Institute of Hygiene, Rabat, Morocco for his cooperation.

\section{REFERENCES}

[1] RH Orsi, H.C. den Bakker and M. Wiedmann, Listeria monocytogenes lineages: Genomics, evolution, ecology, and phenotypic characteristics, International Journal of Medical Microbiology, 301(2), 2011, 79-96.

[2] MW Gilmour, M. Graham, G. Van Domselaar, S. Tyler, H. Kent, K. M. Trout-Yakel, O. Larios, V. Allen, B. Lee and C. Nadon, High-throughput genome sequencing of two Listeria monocytogenes clinical isolates during a large foodborne outbreak, BMC Genomics, 11, 2010, 120-135.

[3] A Leclercq, V. Chenal-Francisque, H. Dieye, T. Cantinelli, R. Drali, S. Brisse, M. Lecuit, Characterization of the novel Listeria monocytogenes PCR serogrouping profile IVb-v1, International Journal of Food Microbiology, 147(1), 2011, 74-77.

[4] P. Waddington, Food Safety Management System Manual (version 2, 2012).

[5] A Galvez, H. Abriouel, N. Benomar and R. Lucas, Microbial antagonists to food-borne pathogens and biocontrol, Current Opinion in Biotechnology, 21(2), 2010, 142-148.

[6] CH Porsby, B. F. Vogel, M. Mohr and L. Gram, Influence of processing steps in cold-smoked salmon production on survival and growth of persistent and presumed non-persistent Listeria monocytogenes, International Journal of Food Microbiology, 122(3), 2008, 287-295.

[7] DA Rodrigues, M. A. Almeida, P. A. Teixeira, R.T. Oliveira and J. C. Azeredo, Effect of batch and fed-batch growth modes on biofilm formation by Listeria monocytogenes at different temperatures, Current Microbiology, 59(4), 2009, 457-462.

[8] M Arevalos-Sánchez, C. Regalado, S.E. Martin, J. Domínguez-Domínguez and B.E. García-Almendárez, Effect of neutral electrolyzed water and nisin on Listeria monocytogenes biofilms, and on listeriolysin O activity. Food Control, 24,(1-2), 2012, 116122

[9] H Takahashi, S. Miya, K. Igarashi, T. Suda, S. Kuramoto and B. Kimura, Biofilm formation ability of Listeria monocytogenes isolates from raw ready-to eat seafood, Journal of Food Protection, 72(7), 2009, 1476-1480.

[10] PS Ibusquiza, J. J. R. Herrera, D. Vázquez-Sánchez and M. L. Cabo, Adherence kinetics, resistance to benzalkonium chloride and microscopic analysis of mixed biofilms formed by Listeria monocytogenes and Pseudomonas putida, Food Control, 25(1), 2012, 202-210.

[11] ND Andritsos, M. Mataragas, S. Paramithiotis and E.H. Drosinos, Quantifying Listeria monocytogenes prevalence and concentration in minced pork meat and estimating performance of three culture media from presence/absence microbiological testing using a deterministic and stochastic approach, Food Microbiology, 36(2), 2013, 395-405.

[12] PK Mandal, A.K. Biswas, K. Choi and U.K. Pal, Methods for rapid detection of foodborne pathogens: an overview, American Journal of Food Technology, 6(2), 2011, 87-102.

[13] V Jasson, L. Jacxsens, P. Luning, A. Rajkovic and M. Uyttendaele, Alternative microbial methods: An overview and selection criteria, Food Microbiology, 27(6), 2010, 710-730.

[14] H Ennaji, M. Timinouni, M.M. Ennaji, R. Ait m'hand, M. Hassar and N. Cohen, Rapid detection of Listeria monocytogenes in food by polymerase chain reaction, Cellular and Molecular Biology, 55, 2009, 1104-1110.

[15] M. Zunabovic, K. J. Domig and W. Kneifel, Practical relevance of methodologies for detecting and tracing of Listeria monocytogenes in ready-to-eat foods and manufacture environments, LWT - Food Science and Technology, 44(2), 2011, 351-362.

[16] K Warriner and A. Namvar, What is the hysteria with Listeria?, Trends in Food Science \& Technology, 20(6-7), $2009,245-254$.

[17] DM Norton, Polymerase chain reaction-based methods for detection of Listeria monocytogenes: toward real-time screening for food and environmental samples, Journal of AOAC International, 85(2), 2002, 505-515.

[18] NP Rijpens and L.M. Herman, Molecular methods for identification and detection of bacterial food pathogens, Journal of AOAC International, 85(4), 2002, 984-995.

[19] MM Janzten, J. Navas, A. Corujo, R. Moreno, V. López and J. V. Martínez-Suárez, Specific detection of Listeria monocytogenes in foods using commercial methods: from chromogenic media to real-time PCR, Spanish Journal of Agricultural Research, 4(3), 2006, 235-247.

[20] TM Benetti, C. L. B. Monteiro, M. R. Beux and W. M. Abrahão, Comparison of selective agars recommended by method ISO 11290-1 and chromogenic agars for the isolation of Listeria sp. in refrigerated sausages, Brazilian Journal of Pharmaceutical Sciences, 48(4), 2012, 677-681

[21] ISO 11290-1, Microbiology of food and animal feeding stuffs - Horizontal method for the detection and enumeration of Listeria monocytogenes - Part 1: Detection method, International Standard ISO 11290-1, International Organization for Standardization (ISO), 1996, Geneva, Switzerland.

[22] ISO 22119, Microbiology of food and animal feeding stuffs -- Real-time polymerase chain reaction (PCR) for the detection of foodborne pathogens -- General requirements and definitions, International Organization for Standardization (ISO), 2011, Geneva, Switzerland. 
[23] ISO/TS 20836, Microbiology of food and animal feeding stuffs -- Polymerase chain reaction (PCR) for the detection of food-borne pathogens -- Performance testing for thermal cyclers, International Organization for Standardization (ISO), 2005, Geneva, Switzerland.

[24] ISO 20837, Microbiology of food and animal feeding stuffs -- Polymerase chain reaction (PCR) for the detection of food-borne pathogens -- Requirements for sample preparation for qualitative detection, International Organization for Standardization (ISO), 2006, Geneva, Switzerland.

[25] ISO 20838, Microbiology of food and animal feeding stuffs -- Polymerase chain reaction (PCR) for the detection of food-borne pathogens -- Requirements for amplification and detection for qualitative methods, International Organization for Standardization (ISO), 2006, Geneva, Switzerland.

[26] A Parisi, L. Latorre, G. Normanno, A. Miccolupo, R. Fraccalvieri, V. Lorusso and G. Santagada, Amplified fragment length polymorphism and multi-locus sequence typing for high-resolution genotyping of Listeria monocytogenes from foods and the environment, Food Microbiology, 27(1), 2010, 101-108.

[27] JO Grady, M.Ruttledge, S. S. Balbás, T. J. Smith, T. Barrya and M. Maher, Rapid detection of Listeria monocytogenes in food using culture enrichment combined with real-time PCR. Food Microbiology, 26(1), 2009, 4-7.

[28] KK Srivastava, S. Nadeem, and P. G. Reddy, Rapid Detection of Listeria monocytogenes in Ground Turkey Meats by Immunomagnetic Separation (IMS) and Real Time- Polymerase Chain Reaction, Journal of Food Safety, 11(2), $2009,50-54$.

[29] K Fantelli and R. Stephan, Prevalence and characteristics of Shiga toxinproducing Escherichia coli and Listeria monocytogenes strains isolated from minced meat in Switzerland, International Journal of Food Microbiology, 70(1-2), 2001, 63-69.

[30] VM Bohaychuck, G. E. Gensler, R.K. King, K.I. Manninen, O. Sorensen, J.T. Wu, M.E. Stiles and L.M. McMullen, Occurrence of pathogens in raw and ready to- eat meat and poultry products collected from the retail market place in Edmonton, Alberta, Canada, Journal of Food Protection, 69 (9), 2006, 2176-2182.

[31] LA Nero, M.R. de Mattos, A. Barros Mde, M.B. Ortolani, V. Beloti and B.D. Franco, Listeria monocytogenes and Salmonella spp. in raw milk produced in Brazil: occurrence and interference of indigenous microbiota in their isolation and development, Zoonoses Public Health, 55(6), 2008, 299-305.

[32] LA Nero, M. R. de Mattos, A. M. Aguiar, A. Barros Mde, V. Beloti and B.D. Franco, Interference of raw milk autochthonous microbiota on the performance of conventional methodologies for Listeria monocytogenes and Salmonella spp. Detection, Microbiological Research, 164(5), 2007, 529-535.

[33] Centre for Disease Control and Prevention (CDC), Preliminary Food Net data on the incidence of infection with pathogens transmitted commonly through food - 10 states in 2008, Morbidity and Mortality Weekly Report, 58, 2009, 333-338.

[34] R Betts and C.W Blackburn, Detecting pathogens in food. In: Foodborne pathogens: hazards, risk analysis and control, Woodhead Publishing, 2(CRC Press, Oxford, UK, 2009), 17-65. 